\title{
A Quantitative Study of the Interactions between Oil Price and Renewable Energy Sources Stock Prices
}

\author{
Goran Dominioni ${ }^{1}$, Alessandro Romano ${ }^{2}$ and Chiara Sotis ${ }^{3, *}$ \\ 1 Rotterdam Institute of Law and Economics, Erasmus University Rotterdam, 3062 PA Rotterdam, \\ The Netherlands; dominioni@law.eur.nl \\ 2 Yale Law School, Yale University, New Haven, CT 06520, USA; alessandro.romano@yale.edu \\ 3 Department of Geography and Environment, London School of Economics and Political Science, \\ London WC2A 2AE, UK \\ * Correspondence: c.sotis@lse.ac.uk; Tel.: +44-07521-203314
}

Received: 3 April 2019; Accepted: 27 April 2019; Published: 5 May 2019

\begin{abstract}
In this article, we apply an integrable nonautonomous Lotka-Volterra model to study the relationship between oil and renewable energy stock prices between 2006 and 2016. The advantage of this innovative approach is that it allows us to study the simultaneous interaction among $n$ stock indices at any point in time. In line with previous studies, we find that the relationship between oil and renewables is characterized by major structural breaks taking place in 2008 and around 2013. The first structural break might be caused by the financial crisis, whereas more studies are required to advance a hypothesis on the causes behind the second structural break. Our main finding is that oil is always in a predator-prey relationship with wind, whereas it proceeds in mutualism with solar after 2012. Moreover, we find that solar and wind proceed in mutualism between 2008 and 2013 but have a rivalrous interaction before (competition) and after (predator-prey) that period. We explore the possible reasons behind these patterns and their policy implications.
\end{abstract}

Keywords: Lotka-Volterra; oil prices; renewable energy

\section{Introduction}

One of the key challenges for future generations will be meeting a growing demand for energy. According to recent estimates, the demand for energy will increase by 28\% between 2015 and 2040, with a growing share coming from non-OECD countries [1]. Unless this demand is met in significant part via renewable energy sources, this trend might constitute a threat for the climate and for energy security [2].

Private investments in renewable energy sources can play a key role in sustaining the transition to a greener and more mixed energy supply. In 2016, private finance accounted for about 90 percent of the investments in renewable energy worldwide, with public finance playing an enabling role [3]. Private capitals are particularly needed in developing countries where limited fiscal capacity often hinders sufficient ambition for climate change policies. In this vein, despite the developed countries' pledges to support the Global South in meeting their Nationally Determined Contributions (NDCs) under the Paris Agreement, it is widely recognized that the bulk of the funding will need to come from the private sector to deliver on the two-degree temperature increase target [4]. However, private capitals can be attracted only if renewables are sufficiently profitable. The price of oil is a key determinant of the profitability of renewables [5,6]. It is uncertain, however, in which direction changes in the price of oil affect the profitability of renewable energies. Conventional wisdom holds that higher oil prices incentivize investments in alternative energy sources because they reduce the relative cost of the latter [7]. At the same time, there is ample evidence that when the cost of oil increases, the 
economy stagnates [5], which may have a negative impact on the profitability of investments in renewables. Moreover, higher oil prices negatively affect the production of renewable energy because this production entails the consumption of large amounts of fossil fuels [8,9]. This has an impact on the returns of all energy sources and might ultimately affect a country's growth $[10,11]$. Given that these factors push in opposite directions, it is hard to determine a priori the sign of the relationship between oil and renewables. As importantly, renewables are often treated as a monolithic bloc in the empirical literature $[5,7,12]$. However, it is possible that different types of renewables interact in different ways with oil and that renewables have nuanced patterns of interaction among themselves.

Previous research has investigated the relationship between oil prices and renewable energies using a wide array of methodologies. Using a VAR model, Henriques and Sadorsky [7] find that renewables have a weaker relationship with oil than with technology. These results are partially contradicted by Kumar and Managi [5], who apply a VAR framework and find a statistically significant impact of oil prices on the stock price of clean energy firms. Similarly, Reboredo [6] finds that oil price dynamics determine around $30 \%$ of upside and downside risk faced by renewable energy companies, which suggests a strong relationship between oil and renewables. Managi and Okimoto [13] also investigate the relationship between oil, renewables and technology stock prices. In line with Henriques and Sadorsky [7], they find that the relationship between oil and renewables is weak, at least until 2007. However, they identify a structural break at the beginning of the crisis. After that, they find a positive and statistically significant relationship between oil prices and renewables share prices. Bondia et al. [14] study the relationship between oil and the new energies stock market in a multivariate framework and find that oil prices affect renewables, but only in the short run. Moreover, they confirm the insight of previous research [13] that such a relationship presents structural breaks. This result supports the idea that it is necessary to employ models capable of accounting for changes in the kind of interaction. The closest article to ours is Reboredo et al. [15]. They use discrete and continuous wavelets to study the short- and long-term relationship between oil and renewables. They find no short-term relationship between them, but they observe that such a relationship emerges in the long-term.

To summarize, several studies have analyzed the relationship between oil and renewables, yet their results have often been conflicting. However, all of the studies have converged on the fact that this relationship changes over time. For these reasons, we try to shed new light on this debate by adopting a novel methodology that allows us to capture changes in the way in which energy sources interact. In particular, we use the integrable nonautonomous Lotka-Volterra (LV) model developed in Marasco et al. [16] and Marasco and Romano [17] to study the interaction among energy sources (for a list of the possible kinds of interactions, see Table 1). The advantage of this method is twofold. On the one hand, the interaction coefficients of nonautonomous LV models change over time, and therefore we can capture how patterns of interactions evolve. On the other hand, the solutions of the model are known, and hence we can derive the existing interactions directly from the data in a straightforward manner [18].

In line with previous research [15], we collect daily data on the value of three clean energy indices: (i) the NYSE Bloomberg Global Wind Energy Index (WIND); (ii) the NYSE Bloomberg Global Solar Energy Index (SOLAR); and (iii) the NYSE Bloomberg Global Energy Smart Technologies Index (TECH). As a measure of oil price, we use the West Texas Intermediate (WTI) [14].

Our empirical evidence shows that two structural breaks occurred in 2008 and around 2013, thus confirming the importance of analyzing the interaction between oil prices and alternative energies stock prices using methods that can capture changes in the kind of interaction. The financial crisis might have caused the first structural break since it produced substantial changes in investors' and firms' behavior. However, we refrain from advancing hypotheses on the causes of the second structural break. Moreover, we find that variations in oil prices impact renewable energy indices more than variations in the latter affect the former. This is in line with the standard idea that oil prices play an important role in determining the attractiveness of renewable energy sources. Turning to the kind of 
interactions among the indices considered, we find that oil is always in a predator-prey relationship with WIND, whereas after 2012 it engages in mutualism with SOLAR. Moreover, we observe that SOLAR and WIND proceed in mutualism between 2008 and 2013, while they engage in a rivalrous interaction before (competition) and after (predator-prey) that period. We explore the possible reasons behind these patterns and their policy implications. For instance, we show that the federal subsidies given by the United States government to solar developers between 2008 and 2013 had a positive impact on wind developers. Vice versa, the federal subsidies to solar developers that were given between 2013 and 2014 had a negative impact on wind developers and (partially) neutralized the impact on wind developers of wind subsidies. This finding shows that policymakers should be keenly aware of the existing interactions among renewables and between renwables and oil.

Table 1. Possible kinds of interactions.

\begin{tabular}{llll}
\hline$g_{i}$ & $g_{j}$ & Interaction & Description \\
\hline+ & + & Competition & $\begin{array}{l}\text { An increase (reduction) in the value of one index } \\
\text { negatively (positively) affects the value of the other index. }\end{array}$ \\
\hline- & + & Predator-Prey & $\begin{array}{l}\text { An increase in the value of index A negatively affects the } \\
\text { value of index B (predator). An increase in the value of } \\
\text { index B positively affects index A (prey). }\end{array}$ \\
\hline- & - & Mutualism & $\begin{array}{l}\text { An increase (reduction) in the value of one index increases } \\
\text { (reduces) the value of the other. }\end{array}$ \\
\hline- & 0 & Commensalism & $\begin{array}{l}\text { An increase (decrease) in the value of index A positively } \\
\text { (negatively) affects index B. Index A is unaffected by } \\
\text { changes in B. }\end{array}$ \\
\hline+ & 0 & Amensalism & $\begin{array}{l}\text { An increase (decrease) in the value of index A negatively } \\
\text { (positively) affects index B. Index A is unaffected by } \\
\text { changes in B. }\end{array}$ \\
\hline 0 & 0 & Neutralism & No interaction. \\
\hline
\end{tabular}

\section{Materials and Methods}

To perform the analysis, we collected daily data on four indices for the period of January 6th 2006-November 25th 2016. (Note that the cut-off points are not arbitrary, as the time interval considered covers the entire lifespan of the three indices considered for renewable energy sources. In fact, Bloomberg changed the composition and the name of the indices in November 2016). In line with previous research, we relied on the West Texas Intermediate (WTI) to capture oil price movements $[14,15]$. Moreover, in agreement with Reboredo [15], we used the following three indices for renewable energies share prices: (i) the NYSE Bloomberg Global Wind Energy Index (WIND), which comprises firms operating throughout the wind power sector; (ii) the NYSE Bloomberg Global Solar Energy Index (SOLAR), an index that includes companies active across the solar power sector; and (iii) the NYSE Bloomberg Global Energy Smart Technologies Index (TECH), comprising companies active in the following sectors: energy efficiency and storage, digital energy, and advanced transportation. Data were retrieved from Bloomberg New Energy Finance for renewable indices and from the US Energy Information Agency website. All of the data was transformed into shares, obtained by dividing the price of each index by the sum of all indices. 
Table 2. Descriptive Statistics of the Global Solar Energy Index (SOLAR), Global Energy Smart Technologies Index (TECH), Global Wind Energy Index (WIND), and West Texas Intermediate (WTI) between 2006 and 2016.

\begin{tabular}{ccccc}
\hline & SOLAR & TECH & WIND & WTI \\
\hline Mean & 1206.1 & 1438.2 & 1342.2 & 77.6 \\
Min & 379.7 & 631.6 & 577.1 & 28.14 \\
Max & 3734.6 & 2363.8 & 3009 & 142.5 \\
St. Dev. & 687.5 & 350.6 & 552.7 & 22.9 \\
\hline
\end{tabular}

Table 2 reports the descriptive statistics of the indices considered. One interesting observation is that TECH fluctuates less than WIND and SOLAR. Thus, it seems to be a less risky investment. The WTI also had significant fluctuations during the time period considered, as its maximum value is over 5 time larger than its minimum value. For a comparison, the highest value of TECH is only 3.74 times larger than its lowest value.

Figure 1 describes the market share dynamics of the four indices considered. We observe that SOLAR and WIND gain a significant market share at the beginning of the time interval considered, but their position is eroded by the growth of TECH. Instead, the WTI index peaks around 2008 and 2012-2013. These peaks roughly correspond to the two structural breaks that we identify (see Section 3).

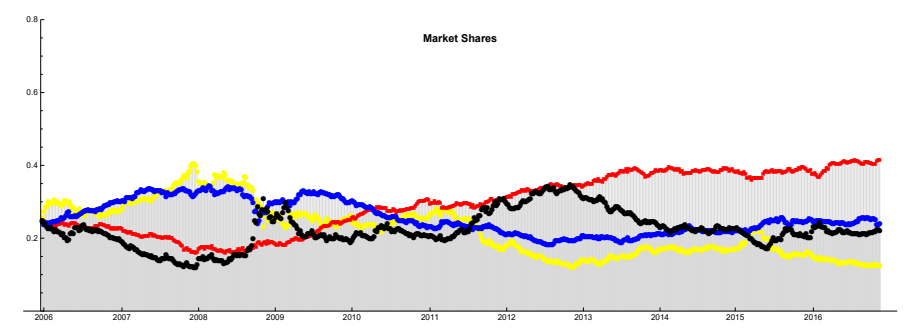

Figure 1. Market shares of WTI, SOLAR, WIND, and TECH across time. WTI has a different scale from SOLAR, WIND, and TECH. Therefore, in this figure we add 1000 to the WTI to avoid it collapsing on the $x$-axis.

To analyze these data, we apply the integrable nonautonomous Lotka-Volterra model developed in Marasco et al. [16] and Marasco and Romano [17]. For an accurate description of the model and the relative formal proof, we refer the reader to Marasco et al. [16]. Lotka-Volterra models have already been used in energy studies (e.g., $[19,20])$. We improve on their approach because we rely on a nonautonomous Lotka-Volterra model, the solutions of which are known. We write each energy share $(E S)$ in the form of a logit model. The energy shares of the $i$ th and of the outside energy source are

$$
\begin{aligned}
& x_{i}(t)=\frac{\exp \left(f_{i}(t)\right)}{1+\sum_{j=1}^{4} \exp \left(f_{j}(t)\right)}, \quad i=1,2,3,4 \\
& x_{0}(t)=\frac{1}{1+\sum_{j=1}^{4} \exp \left(f_{j}(t)\right)}, \quad \forall t \geq t_{0}
\end{aligned}
$$

where the utility function of an energy source $f_{i}(t), i=1, \ldots, 4$ is

$$
f_{i}(t)=\ln \left(\frac{T S_{i}(t)}{T S_{0}(t)}\right), \quad i=1,2,3,4
$$

If all the utility functions $f_{i}(t)$ are of class $C^{2}\left(\left[t_{0},+\infty\right)\right)$, then Equation $(1)_{1}$ is the unique (global) solution of the Cauchy problem. 


$$
\left\{\begin{array}{l}
\dot{x}_{i}(t)=g_{i}(t) x_{i}(t)\left[1-x_{i}(t)\right]-\sum_{j=1, j \neq i}^{4} g_{j}(t) x_{j}(t) x_{i}(t), \quad i=1,2,3,4 \\
x_{i}\left(t_{0}\right)=\frac{\exp \left(f_{i}\left(t_{0}\right)\right)}{1+\sum_{j=1}^{N} \exp \left(f_{j}\left(t_{0}\right)\right)}
\end{array} t \in\left[t_{0},+\infty\right),\right.
$$

where $\dot{x}_{i}(t)=d x_{i}(t) / d t, x_{0}(t)=1-\sum_{i=1}^{4} x_{i}(t)$, and

$$
g_{i}(t)=\dot{f}_{i}(t)=\frac{T S_{i}(t)}{T S_{i}(t)}-\frac{T S_{0}(t)}{T S_{0}(t)}, \quad i=1,2,3,4 .
$$

The nonautonomous LV system (3) describes the interaction between the $i$ th and $j$ th energy source. The energy share depends on the logistic growth rate function $g_{i}(t)$ and the interaction functions $g_{j}(t)$ between the $i$ th and $j$ th energy sources. The maximum capacity of each energy source is equal to one. The kind of interaction among energy sources is determined by the sign of the functions $g_{i}(t)$ and $g_{j}(t)$. The utility functions $f_{i}(t)$ are defined as nonlinear combinations of time-varying variables $V_{h}, h=1, \ldots, M$. The energy share of the $i$ th energy source increases when its utility function $f_{i}(t)$ increases, and decreases when the utility function $f_{j}(t)$ of any other energy source increases. Equation (1) allows us to evaluate how changes in the utility functions affect the energy shares. Importantly, the available data are not on the utility functions, but on the energy shares. The utility functions are determined from the historical data on energy shares via a fitting procedure. As standard in the mathematical literature, in this article the fitting procedure is performed using a Fourier series. An example of fitting is reported in Figure 2.

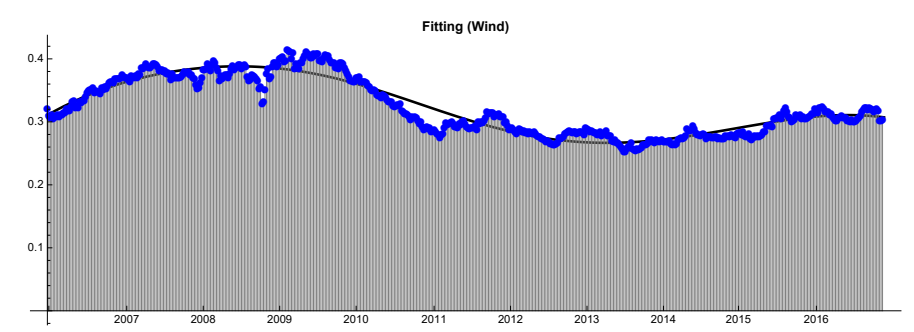

Figure 2. Fitting of WIND between 2006 and 2016 using a Fourier series.

The advantages of this approach are manifold. First, since the interaction coefficients are dependent on time, our model allows us to capture structural changes. Second, because the solutions of the model are known, we do not have to estimate the parameters using expensive numerical methods like genetic algorithms [21]. Instead, we can derive the competitive roles directly from the data. Third, the solution of this LV model is the logit model, which has been used extensively to model the choice among alternative energy sources [22-24]. Therefore, our approach is consistent with that of the mainstream literature.

\section{Accuracy of the Model}

We assess the accuracy and reliability of our model using two standard measures of error: the mean square error (MSE) and the mean absolute percentage error (MAPE). Following Lewis [25], we consider our model to be highly accurate if $M A P E<10 \%$, good for $10 \%<M A P E<20 \%$, reasonable for $10 \%<M A P E<50 \%$, and inaccurate if $M A P E>50 \%$.

MSE and MAPE are calculated as follows.

$$
M S E=\frac{1}{n} \sum_{i=1}^{n}\left(h_{i}-p_{i}\right)^{2}, \quad M A P E=\frac{1}{n} \sum_{i=1}^{n}\left|\frac{h_{i}-p_{i}}{h_{i}}\right| 100 \%,
$$


where $h_{i}$ and $p_{i}$ are, respectively, the historical and predicted values.

The measures of error are reported in Table 3.

Table 3. Mean square error (MSE) and mean absolute percentage error (MAPE) for the four indices considered.

\begin{tabular}{lll}
\hline Energy Source & MSE & MAPE \\
\hline Solar & 0.000793627 & 7.99783 \\
Tech & 0.000397221 & 5.03432 \\
Wind & 0.000208529 & 3.49197 \\
WTI & 0.000014568 & 16.1362 \\
\hline
\end{tabular}

The measures of errors considered reveal that our model is, on average, highly accurate.

\section{Results}

Figure 3 shows the relations between all indices, with time on the horizontal axis and the interaction coefficient on the vertical axis. In line with previous works, we observe that the kind of interaction among the indices changes over time [13] and can be nonlinear [15]. In particular, similarly to Bondia et al. [14], we find evidence of two structural breaks: one in 2008 and the other around 2012-2013. At these critical junctures, the kind of interaction between each pair of indices changes. The first structural break might be a consequence of the economic crisis and strong fluctuations in oil prices [13]. In contrast, understanding the causes behind the second structural break requires further studies. At a more general level, our findings highlight that the study of oil-renewables dynamics requires methods that can capture changes in the way in which energy sources interact with each other. The interaction coefficients also indicate that the interaction among TECH, SOLAR, and WIND weakens in intensity in the period of 2013-2016, suggesting that as alternative energy industries become more important, their interdependence decreases. We also find that changes in WTI have a stronger impact on renewable energy indices than changes in the latter have on the WTI.

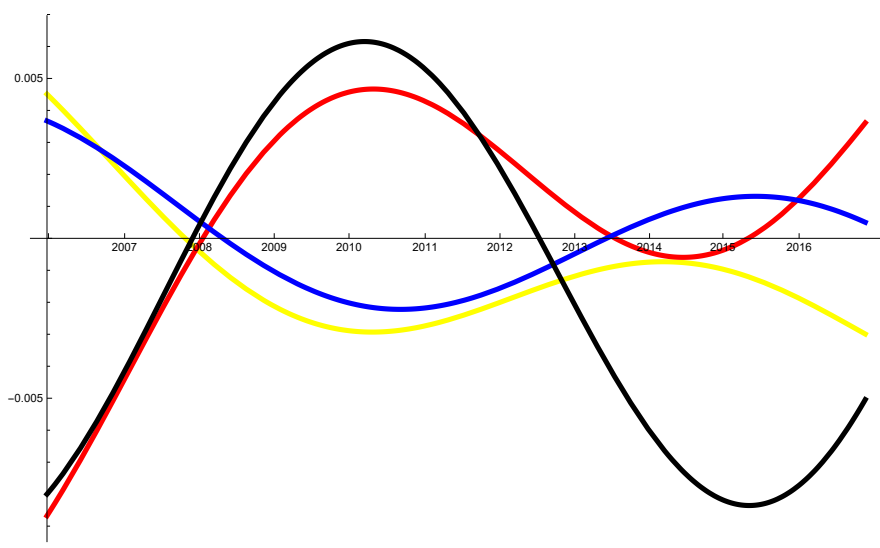

Figure 3. The $x$-axis represents time. The $y$-axis represents the value of the interaction coefficients of SOLAR (yellow), WIND (blue), WTI (black), and TECH (red) between 2006 and 2016.

Figure 4 represents the interactions between WTI, SOLAR, and WIND. Until 2008, SOLAR and WIND are in a predator-prey relationship with WTI and in which the renewables are the prey. This might be because investments in renewables still largely implied the use of fossil fuels in production [8,9], and thus higher demand for renewables also implied higher demand for fossil fuels. This mirrors a predator-prey interaction in which an increase in the number of prey benefits the predator. The opposite, however, does not hold because the production of fossil fuels does not strictly rely on renewable energy. In 2008, the renewable energy indices and WTI switch roles, and the former starts predating on oil. 


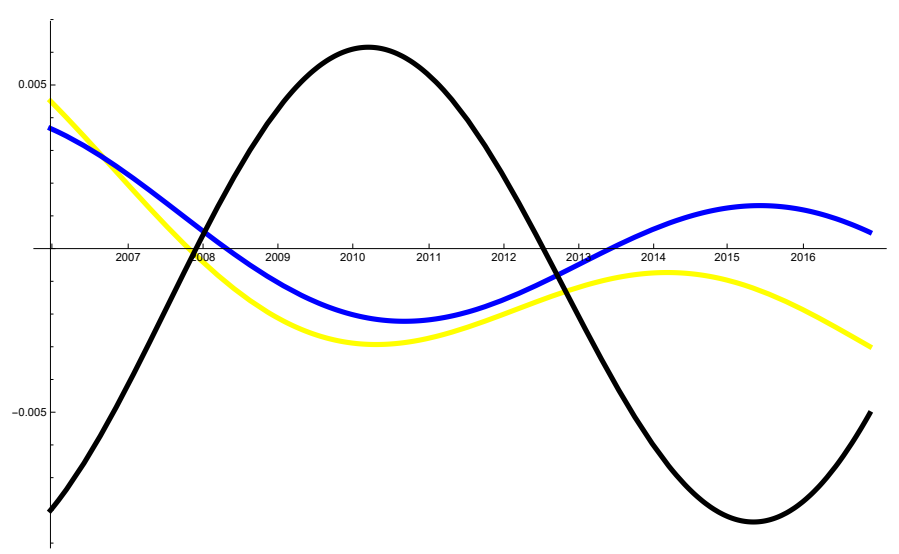

Figure 4. The $x$-axis represents time. The $y$-axis represents the value of the interaction coefficients of SOLAR (yellow), WIND (blue), and WTI (black) between 2006 and 2016.

Figure 5 shows the interaction between WTI and TECH. They proceed in mutualism until 2008, and after the structural break they switch to competition until the second structural break in 2013. In the aftermath of the second structural break, they engage predominantly in a predator-prey relationship, with TECH being the prey.

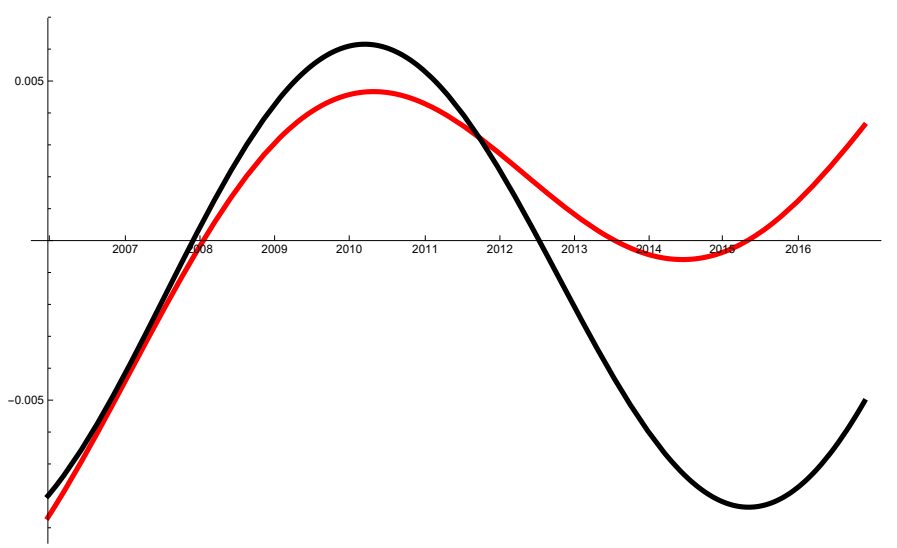

Figure 5. The $x$-axis represents time. The $y$-axis represents the value of the interaction coefficients of TECH (red) and WTI (black) between 2006 and 2016.

Figure 6 shows the relationship between TECH, SOLAR, and WIND. Here, we focus on the interactions between TECH, on one side, and SOLAR and WIND, on the other side. TECH is always in a predator-prey relationship with SOLAR and WIND, with the exception of a period of mutualism between TECH and SOLAR in 2014. These predator-prey interactions are difficult to interpret and call for additional research.

Figure 7 illustrates that the relationship between SOLAR and WIND is characterized by two main structural changes, dividing three markedly different phases. In the first phase, between 2006 and 2008, SOLAR and WIND are competing. In the second phase, between 2008 and 2013, SOLAR and WIND proceed in mutualism. In the last phase, instead, WIND and SOLAR enter a low-intensity predator-prey relation, with WIND as the prey. Understanding the causes behind these forms of interaction should be the subject of future research. A possible determinant of these interactions could be the cost of producing energy through solar and wind. In fact, the costs associated with these two sources evolved very differently (Figure 8). In 2009, the cost of producing solar energy was over 3 times higher than that of producing energy using wind. However, by 2016 the cost of solar and wind were almost identical. 


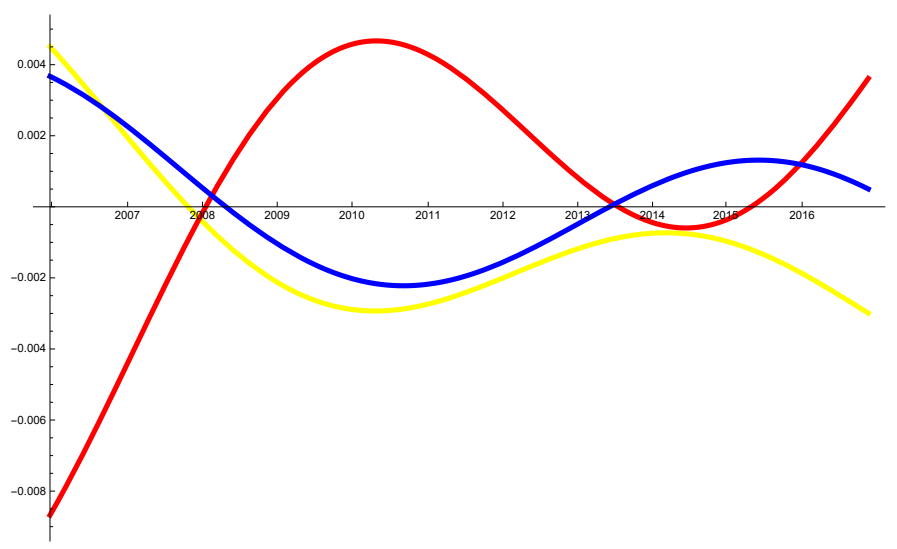

Figure 6. The $x$-axis represents time. The $y$-axis represents the value of the interaction coefficients of SOLAR (yellow), WIND (blue), and TECH (red) between 2006 and 2016.

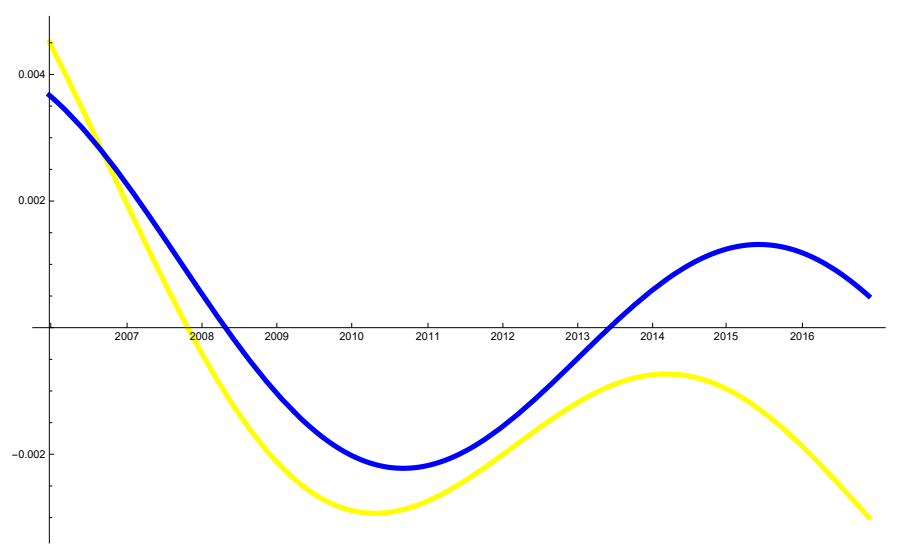

Figure 7. The $x$-axis represents time. The $y$-axis represents the value of the interaction coefficients of SOLAR (yellow) and WIND (blue) between 2006 and 2016.

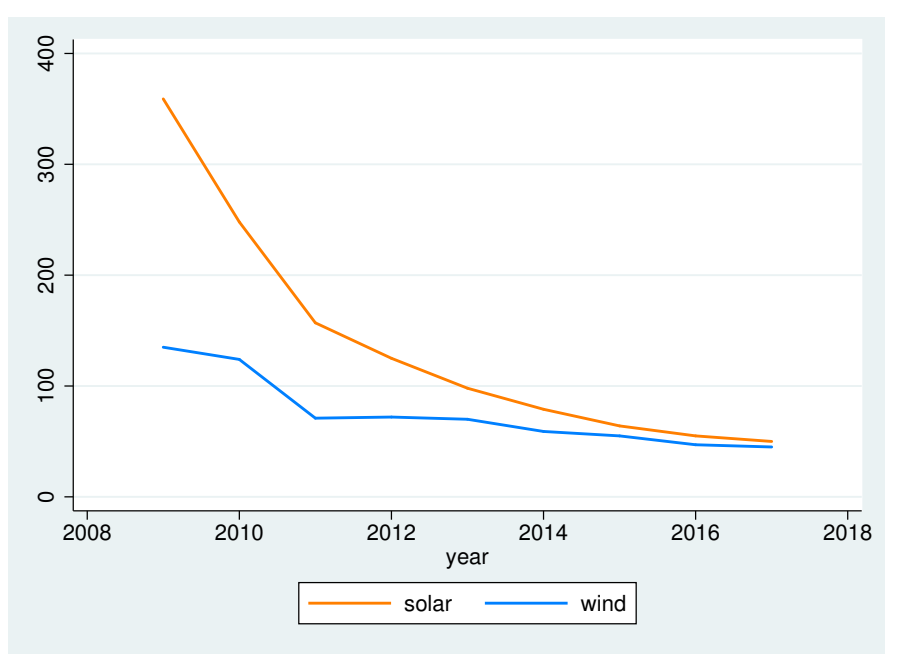

Figure 8. Historical mean levelized cost of energy for WIND and SOLAR between 2009 and 2017.

\section{Discussion}

Our findings have implications for both policymakers and investors. One important factor to consider is whether policymakers can alter the interactions (i.e., the interactions are endogenous for policymakers) or not (i.e., the interactions are exogenous for policymakers). In the former case, policymakers might attempt to favor the emergence of the desired form of interaction, whereas in the latter they might attempt to exploit existing interactions. While our results do not allow us to 
determine with certainty whether the interactions are exogenous or endogenous, there are reasons to believe that in most instances policymakers cannot alter existing interactions. On the one hand, most local policymakers simply do not have enough influence to alter dynamics at a global level. On the other hand, structural breaks are very rare despite the myriad of policies related to renewable energies implemented between 2006 and 2016. This suggests that almost the totality of such policies did not change the kind of interaction among energy sources. Thus, while we cannot rule out exceptions, it seems reasonable to assume that in most instances, policymakers can consider the interactions exogenous. Importantly, besides being hard to conceive, policy aimed at altering existing interactions might easily backfire. For instance, one intuitively appealing goal for policymakers could be fostering mutualism among renewables to generate a positive reinforcing loop of influence among them. However, in a mutualistic relationship a reduction in the attractiveness of one renewable also harms the others. In other words, mutualism is not only a win-win but also a lose-lose relationship. In this vein, a competitive (win-lose) relationship might at times be preferable to minimize the risk of triggering a vicious circle of negative spillovers from one renewable to another.

More promising — and apparently more realistic—are policies that attempt to exploit existing forms of interactions. For instance, fuel taxes or fossil fuel subsidies can be fine-tuned to account for the forecasted interactions. In periods of competition between renewables and oil lowering fuel taxes or increasing fuel subsidies would favor investments in renewables. The same effect would be reached when renewables are prey in a predator-prey relation with oil. Vice versa, when there is mutualism between renewables and oil increasing fuel taxes or reducing fossil fuel subsidies could benefit renewables.

To be sure, our model cannot offer guidance on the optimal level of taxes and subsidies, but its key insight is that policymakers should be keenly aware of the existing kinds of interactions among renewable energy sources and between renewable energy sources and oil. In fact, the same subsidy (or tax) can have very different spillovers depending on the existing forms of interactions. For instance, consider the case of the United States. Between 2008 and 2014, it provided federal subsidies to wind and solar developers worth $\$ 24$ billion [26].During 2008 and 2013, SOLAR and WIND were proceeding in mutualism, and therefore each dollar spent subsidizing one energy source also generated a benefit for the other. In other words, the two subsidies enhanced their respective values. After 2013, however, SOLAR and WIND entered in a predator-prey relationship in which SOLAR was the predator. For this reason, each dollar spent subsidizing solar energy had a negative impact on WIND. Or, to put it differently, the subsidies to solar energy were neutralizing — at least in part-the impact of wind subsidies on WIND.

Investors can also learn from our results because the effectiveness of hedging strategies can be affected by the kinds of interactions existing among energy sources. More precisely, when two indices are in competition (e.g., oil and TECH in 2008-2012) a decrease in value of one benefits the other. This is consistent with the idea of hedging. On the contrary, when two indices are in a mutualistic relationship (e.g., SOLAR and WIND in 2008-2014), a decrease of one harms the other. Similarly, stocks that are in a predator-prey relationship might also not be suitable for hedging. In fact, a decrease in the prey index would also harm the predator index. It is important to remark, however, that the interactions among stocks are not the only determinant of their price dynamics. Thus, investing in oil and renewables might still be a good way of hedging risk even when they are in competition. The claim advanced here is narrow: everything else being equal, stocks that are in competition are better for hedging than stocks that are in mutualism or a predator-prey relationship.

\section{Conclusions}

In this article, we use an integrable nonautonomous Lotka-Volterra model to study the interactions among oil and renewable energy stock prices between 2006 and 2016. Our key findings can be summarized as follows. First, the relationship among the indices considered is characterized by two structural breaks in 2008 and around 2013. Since the first structural break takes places during the 
financial crisis, there might be a causal relationship between the two events. In particular, the financial crisis had a profound impact on the behavior of firms, investors, and policymakers, and hence it stands to reason that it produced significant changes in the interactions among renewables and oil. In contrast, we do not speculate on the causes behind the second structural break. Given the presence of structural breaks, research on the interaction between oil and renewable energy sources must be carried out with methods that allow researchers to capture changes in the interactions. Second, the effect of changes in oil prices on renewables indices is stronger than the effect of the latter on the former. This is in line with the standard idea that oil prices play an important role in determining the attractiveness of renewable energy sources. Turning to the types of interactions, we observe that oil is in a predator-prey relationship with wind for the entire period considered. Instead, oil has a mutualistic relationship with solar after 2012. We also study the relationship between renewables, and in particular between solar and wind. We find that they proceed in mutualism between 2008 and 2013 but have a rivalrous interaction before (competition) and after (predator-prey) that period. We explore the possible reasons behind these patterns and their policy implications. Understanding the interactions between oil prices and renewable energy stock prices can help policymakers and investors' decision-making. In particular, policymakers may try to exploit existing interactions to support renewable energy investments via fiscal policies on oil, whereas investors can exploit interactions to improve their hedging strategies.

Author Contributions: These authors contributed equally to this work.

Funding: This research received no external funding.

Conflicts of Interest: The authors declare no conflict of interest.

\section{Abbreviations}

The following abbreviations are used in this manuscript:

LV Lotka-Volterra

NDCs Nationally determined contributions

OECD Organisation for Economic Co-operation and Development

WIND NYSE Bloomberg Global Wind Energy Index: an index composed of companies active across the wind energy value chain, including the manufacture of wind energy equipment and the financing, development, and operation of wind projects.

SOLAR NYSE Bloomberg Global Solar Energy Index: an index comprised of companies active across the solar energy value chain, including the manufacture of solar energy equipment and the financing, development, and operation of projects.

TECH NYSE Bloomberg Global Energy Smart Technologies Index: an index including companies active across the advanced transportation, digital energy, energy efficiency, and energy storage sectors.

WTI West Texas Intermediate: a grade of crude oil used as a benchmark in oil pricing, the underlying commodity of New York Mercantile Exchange's oil futures contracts.

MSE Mean square error

MAPE Mean absolute percentage error

VAR Vector Autoregression

\section{References}

1. Energy International Agency (EIA). International Energy Outlook; Energy International Agency: Paris, France, 2017.

2. Perea-Moreno, M.A.; Hernandez-Escobedo, Q.; Perea-Moreno, A.J. Renewable Energy in Urban Areas: Worldwide Research Trends. Energies 2018, 11, 577. [CrossRef]

3. International Renewable Energy Agency (IRENA). Global Landscape of Renewable Energy Finance; International Renewable Energy Agency: Abu Dhabi, UAE, 2018.

4. International Finance Corporation (IFC). Creating Markets for Climate Business Report; International Finance Corporation: Washington, DC, USA, 2017. 
5. Kumar, S.; Managi, S. Stock prices of clean energy firms, oil and carbon markets: A vector autoregressive analysis. Energy Econ. 2012, 34, 215-226. [CrossRef]

6. Reboredo, J.C. Is there dependence and systemic risk between oil and renewable energy stock prices? Energy Econ. 2015, 48, 32-45. [CrossRef]

7. Henriques, I.; Sadorsky, P. Oil prices and the stock prices of alternative energy companies. Energy Econ. 2008, 30, 998-1010. [CrossRef]

8. Fthenakis, V.M.; Kim, H.C. Greenhouse-gas emissions from solar electric- and nuclear power: A life-cycle study. Energy Policy 2007, 35, 2549-2557. [CrossRef]

9. Tsai, B.; Chang, C.; Chang, C. Elucidating the consumption and $\mathrm{CO}_{2}$ emissions of fossil fuels and low-carbon energy in the United States using Lotka-Volterra models. Energy 2016, 100, 416-424. [CrossRef]

10. Apergis, N.; Payne, J. Renewable energy consumption and growth in Eurasia. Energy Econ. 2010, 32, $1392-1397$. [CrossRef]

11. Apergis, N.; Payne, J. Renewable energy consumption and economic growth: Evidence from a panel of OECD countries. Energy Policy 2010, 38, 656-660. [CrossRef]

12. Sadorsky, P. Correlations and volatility spillovers between oil prices and the stock prices of clean energy and technology companies. Energy Econ. 2012, 34, 248-255. [CrossRef]

13. Managi, S.; Okimoto, T. Does the price of oil interact with clean energy prices in the stock market? Jpn. World Econ. 2013, 27, 1-9. [CrossRef]

14. Bondia, R.; Ghosh, S.; Kanjilal, K. International crude oil prices and the stock prices of clean energy and technology companies: Evidence from non-linear cointegration tests with unknown structural breaks. Energy 2016, 101, 558-565. [CrossRef]

15. Reboredo, J.C.; Rivera-Castro, M.A.; Ugolini, A. Wavelet-based test of co-movement and causality between oil and renewable energy stock prices. Energy Econ. 2017, 61, 241-252. [CrossRef]

16. Marasco, A.; Picucci, A.; Romano, A. Market Share Dynamics Using Lotka-Volterra Models. Technol. Forecast. Soc. Chang. 2016, 105, 49-62. [CrossRef]

17. Marasco, A.; Romano, A. Inter-port interactions in the Le Havre-Hamburg range: A scenario analysis using a nonautonomous Lotka-Volterra model. J. Transp. Geogr. 2018, 69, 207-220. [CrossRef]

18. Romano, A. A study of tourism dynamics in three Italian regions using a nonautonomous integrable Lotka-Volterra model. PLoS ONE 2016, 11, e0162559. [CrossRef]

19. Pao, H.; Fu, H. Competition and stability analyses among emissions, energy, and economy: Application for Mexico. Energy 2015, 82, 98-107. [CrossRef]

20. Pao, H.; Chen, H.; Li, Y. Competitive dynamics of energy, environment, and economy in the U.S. Energy 2015, 89, 449-460. [CrossRef]

21. Michalakelis, C.; Christodoulos, C.V.D.; Sphicopoulos, T. Dynamic estimation of markets exhibiting a prey-predator behavior. Expert Syst. Appl. 2012, 39, 7690-7700. [CrossRef]

22. Bergmann, A.; Hanley, N.; Wright, R. Valuing the attributes of renewable energy investments. Energy Policy 2006, 34, 1004-1014. [CrossRef]

23. Borkers, A.M.; Dukea, A.M. Does willingness to pay for green energy differ by source? Energy Policy 2007, 35, 3327-3334. [CrossRef]

24. Scarpa, R.; Willis, K. Willingness-to-pay for renewable energy: Primary and discretionary choice of British households' for micro-generation technologies. Energy Econ. 2010, 32, 129-136. [CrossRef]

25. Lewis, C.D. Industrial and Business Forecasting Methods: A Practical Guide to Exponential Smoothing and Curve Fitting; Butterworth Scientific: Oxford, UK, 1982.

26. Chediak, M.; Martin, C. Say Goodbye to Solar Power Subsidies; Bloomberg: New York, NY, USA, 2015.

(C) 2019 by the authors. Licensee MDPI, Basel, Switzerland. This article is an open access article distributed under the terms and conditions of the Creative Commons Attribution (CC BY) license (http:/ / creativecommons.org/licenses/by/4.0/). 